\title{
Collaboration for Impact: Involving Stakeholders in Ethnographic Research
}

\author{
Jennifer Watts-Englert \\ Xerox Innovation Group
}

Margaret H. Szymanski
Xerox Innovation Group

\author{
Patricia Wall \\ Xerox Innovation Group \\ Mary Ann Sprague \\ Xerox Innovation Group
}

\begin{abstract}
Over time, our corporate ethnographic methods have evolved to engage and involve stakeholders in our research projects to an increasing degree. Stakeholder engagement ranges from peripheral beneficiary to champion promoter, to research partner to study participant. This paper uses case studies to illustrate different kinds of collaborations we have used to engage stakeholders: 1) Advisory board, 2) Field visits with subject matter experts, 3) Analytic data sessions, 4) Co-design as an iterative research process, and 5) Competency transfer. Based on our experiences we discuss ways of managing stakeholder involvement and the impacts that our collaborations with stakeholders have had at all levels of the organization While it can be challenging to involve stakeholders in the research process, when they do become part of the research team, we have found that our research creates more impact. "Stakeholders can help us determine implications for research findings and they are often in the position to take action based on these findings, and/or to advocate for incorporating these findings in business process improvements and product development."
\end{abstract}

\section{INTRODUCTION}

Corporate research labs are on the decline. Economic hard times have caused corporate research headcount reductions and compelled researchers to look for external funding for their research agendas. According to Slywotzky (2009:5 $5^{\text {th }}$ paragraph), "since the 1990s, labs dedicated to pure research-to the pursuit of scientific discovery - have seen funding slowly decline and their mission shift from open-ended problem solving to short-term commercial targets, from pure discovery to applied research." These increasing economic pressures are requiring corporate researchers to create and demonstrate a clear impact on corporate processes and offerings. At Xerox, we have found that our ethnographic research makes a bigger impact when we involve stakeholders in the research process. 
Ethnography in corporate research, referred to as Work Practice Study within Xerox, was pioneered more than 30 years ago at Xerox PARC (now PARC Inc.). Xerox founded Xerox PARC as a pure research laboratory with the goal of creating the Office of the Future; anthropologists were called in to enable human-centered innovation and design of technology and better ways of working. Lucy Suchman $(1995,2011)$ formalized the methodology at Xerox PARC by establishing the Work Practice and Technology group in 1989. Over the years, Xerox's ethnographic orientation proliferated to include ethnomethodology and conversation analysis, participatory design and visual co-design practices. Today four Xerox research centers - in California, New York, France and India - have work practice competency; all work towards the holistic understanding of people's activities in technology rich environments through the naturalistic observation, recording and analysis of these activities. Across the history of Work Practice within Xerox, our methods have evolved to engage the stakeholders of the research to greater degrees (See Figure 1).

FIGURE 1

PROGRESSION OF XEROX ETHNOGRAPHY PROJECTS (DEKLEER, WHALEN, WHALEN 2004)

\section{From critique...}

to engaged experimentation and intervention...

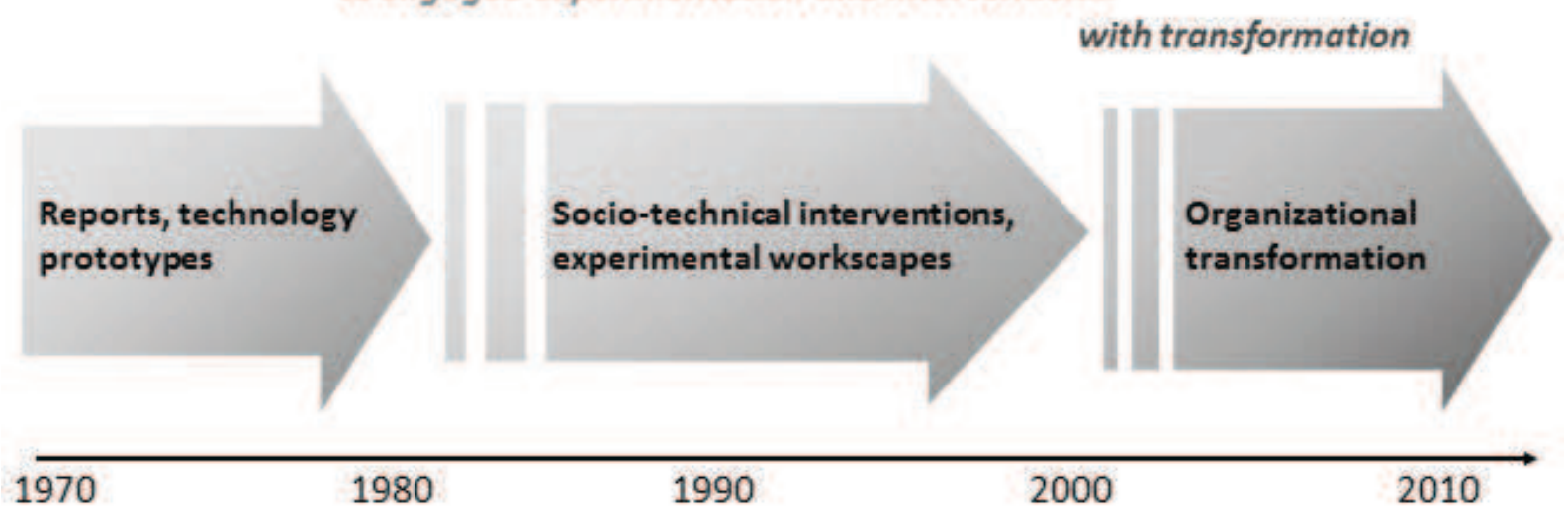

Over the years, the focus of our work practice projects has moved from the critique and description of a particular setting's technology use and work practice to full engagement with the client to achieve organizational and service offering transformation. Along this work practice project continuum, some projects have focused on, for example, the study of entire workscapes (Whalen and Whalen 2004), in airports (Suchman 1992, 1996), call centers (Whalen and Whalen 2011), mobile work (Watts-Perotti et. al, 2012), production printing (Sprague et al., 2007, Colombino et. al. 2011) and academic institutions (Wall et al. 2008). Other projects have involved the capture of the worker's knowledge and experience in socio-technical tools that helped facilitate better ways of working (Whalen and Bobrow 2011; Wall and Koomen 2011).

As stakeholders have become more involved in all stages of ethnographic research, this research has become more instrumental in transforming business and work practices (e.g. Kishimoto 2011; Plurkowski et al. 2011). This trend to directly involve stakeholders has created a radical shift in the way clients think about the utility of ethnographic methods. Whereas corporate ethnography was once only a research competency, it is now conceived of as a powerful tool to propagate organizational change, renovate a business culture and even add to an organization's external service offerings.

In order to create this kind of transformative impact, stakeholders must be closely involved in the ethnographic research. Through myriad techniques, ethnographers at Xerox have developed a dialogue between research and business groups -- many from companies that have not historically invested in 
social science research -- resulting in better uptake of study findings, customer-focused business initiatives, and a rise in partnership opportunities with customers. While it can be challenging to maintain the rigor of ethnographic research when stakeholders become part of the research team, we have found that these challenges can be mitigated and that the benefits are worth the extra up-front investment.

\section{WHAT IS A STAKEHOLDER?}

Mirriam-Webster.com defines stakeholder as "one who is involved in, or is affected by a course of action." We consider anyone who might benefit from and/or act upon the findings of an ethnographic study to be a potential stakeholder. At Xerox, there are various levels of stakeholders who are invited to become involved in ethnographic research, ranging from research and business groups whose work could benefit from the findings of studies that have already been conducted, to business or research partners who commission an ethnographic study to answer specific research questions.

At one end of collaboration continuum are the peripheral stakeholders who could benefit from, or act upon studies that have already been conducted (see Figure 2). These stakeholders could include research teams, corporate strategists, or business groups whose work is related to the topics that have been studied in a past ethnographic project. For example, in the Xerox Future of Work study, peripheral stakeholders from the Xerox Information Management group were interested in using study findings to inform their strategy and the services they provided to Xerox workers (Watts-Englert et al., 2009, 2011).

Peripheral stakeholder collaborations usually begin with a session in which we share our study findings. We tailor our presentations to the peripheral stakeholder audience by highlighting the findings that are most relevant to the work they do. In addition to presenting study findings, we may also conduct workshops with peripheral stakeholders to discuss the implications of the research for their work, and or to translate study findings into solutions they could develop or offer. This kind of interaction is less collaborative because the peripheral stakeholders were not involved in the creation of the study questions, and findings have been tailored post-hoc to highlight the most relevant information.

A second type of stakeholder is the promoter stakeholder: one who might not benefit directly from study findings but can influence the direction of commissioned research and/or how the research is used within the company. For example, managers who decide which projects get funded are important promoter stakeholders for ethnographic projects. In order to fund a project, they often have to champion it, justifying the cost and defending its value. In addition to funding projects, managers can also identify which groups might benefit from past or future ethnographic studies, and they can provide connections to the groups who might not otherwise be willing to listen to study findings. While promoter stakeholders may not benefit directly from a specific study, we still collaborate with them to define research topics and study questions, and to discuss implications of the research for the company.

Promoter stakeholders may also represent the organizations responsible for customer accounts, and provide entree to study participants. In addition to gaining insights to their customers' practices, promoter stakeholders may look at an ethnographic project as a way to build a stronger relationship with the customers. This collaboration helps the promoter stakeholders better understand the kinds of work we do, and creates buy-in for making use of study findings, and for funding future projects.

Promoter stakeholders are great assets in conducting an ethnographic study especially when time in the client site is limited. These stakeholders can serve as important key contacts at the client site(s) who can participate in the project as a guide or liaison. This 'trusted insider' is familiar with the people, culture and practices in an organization and can help with logistics, make introductions and, in some sense, authorize study participants' interactions with researchers. An example where a guide was an integral enabler of project success was for a field study of airline maintenance crews (Wall and Koomen 2011). In this project, a maintenance expert working at headquarters was identified as our 'guide' for access to several maintenance sites during the course of the project. Since we required access to maintenance areas not normally accessible to the public, our promoter stakeholder negotiated access at each of five sites. It proved extremely helpful that he came up through the ranks of the maintenance organization as he had relationships with each of the sites and knew many members of the maintenance staff personally. 
Partner stakeholders collaborate much more closely with us on ethnographic projects at Xerox. These stakeholders commission ethnographic studies, and become involved in all stages of the research. For example, a business or research group might request an ethnographic study about a specific topic or question that directly informs their work. In this type of partnership, we involve stakeholders in as much of the research as they are willing to participate. Partner stakeholders provide input into study questions, accompany us into the field, participate in analysis sessions, work with us to determine implications of the findings for their work, and help us share the findings with groups who might benefit from the study. We find that our collaborations with partner stakeholders can lead to the transformation of business and work practices because the partner stakeholder is invested in the research - not just financially, but personally as well. They help us tune the research questions and package the findings so they are relevant to the target audience. While we always expand our studies beyond the questions that our stakeholders ask, this tuning is a critical element that determines whether findings are taken up by teams who can act on them (Watts-Perotti et al. 2009).

Another stakeholder that we collaborate with is the participant stakeholder - the person who participates in our studies. When we conduct ethnographic studies, we always offer to present our findings back to participant stakeholders. Participants can benefit from findings by getting an outside perspective on their work, including their strengths and weaknesses. They can also help us refine study findings and help us brainstorm implications for new products and services that they might use.

\section{FIGURE 2 \\ THE FOUR LEVELS OF STAKEHOLDERS}

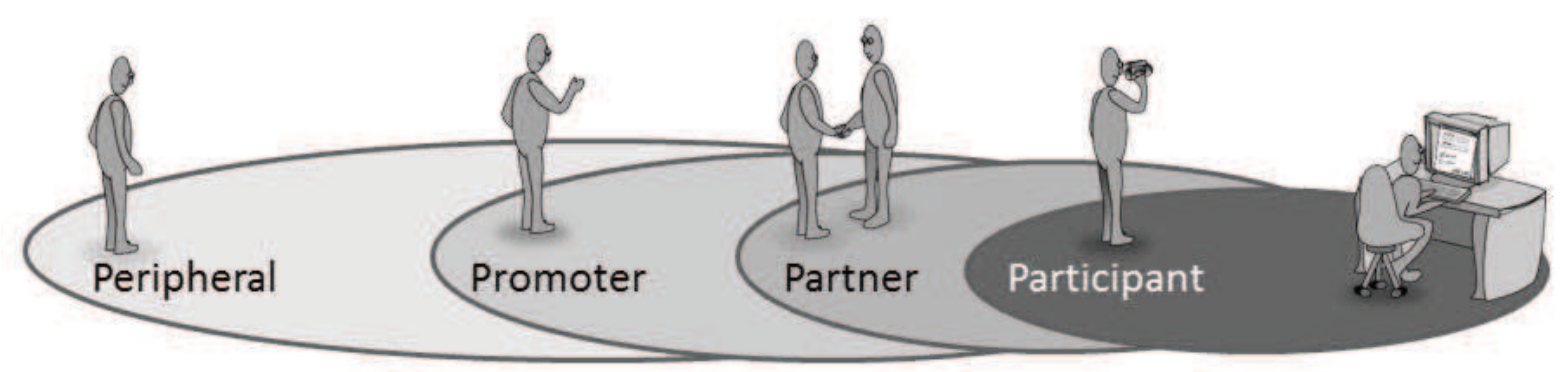

Sometimes, the boundaries between these kinds of stakeholders become blurred. For example, a person might start out as a partner stakeholder, participating in all stages of a research project, and then become a champion, a promoter stakeholder. This happened in a production printing project (Sprague et al., 2007), where a subject matter expert began working with our team as a partner stakeholder, and then became a promoter stakeholder when we began to present results to the technical community. During our presentations, he answered technical questions and vouched for the veracity of the findings, which were quite surprising to the technical community. His promotion of the findings of our study led to the creation of intellectual property, and convinced the company to create a new product offering.

When we work with internal Xerox teams, partner, promoter and peripheral stakeholders can influence the impact a project has within Xerox. Partner stakeholders, often representing services and/or technology interests, look to apply ethnography-inspired insights to inform corporate strategy, product or services innovation. Within the study site, participant and promoter stakeholders bring perspectives that can define what it takes to be successful within that organization as well as identify potential pitfalls the study is likely to encounter. Having stakeholders with different levels of organizational responsibility involved in the study, including management (senior and middle managers), business partners, and participants, enables the researcher to develop a more comprehensive understanding of the work and the factors that influence it. This understanding is very useful to anticipate and mitigate potential risks associated with any recommendations resulting from a study. This was the case for a study of airline 
maintenance crews (Wall and Koomen 2011), where the focus of the study was airline, specifically maintenance crew, compliance in reading and acknowledging new maintenance advisories. Based on the work practice assessment, the team co-designed a solution to address the key issues that impacted those involved in the advisory workflow at every level (headquarters, management, supervisors, and maintenance crews). Understanding how the organization was structured guided the development of the technology and the plan for its roll out.

\section{WAYS OF WORKING WITH STAKEHOLDERS}

As more and more projects engage stakeholders outside the traditional C-level decision makers, methods for engaging them continue to emerge. Within Xerox, we have developed five key ways of working with our stakeholders: 1) Advisory board, 2) Field visits with subject matter experts, 3) Analytic data session, 4) Co-design as an iterative research process, and 5) Competency transfer. These are not mutually exclusive ways of engaging stakeholders. Instead, they are a guide, leaving open the specific combinatory use, which is always dependent upon the negotiated goals of the project.

\section{Advisory board}

When corporate research projects were standalone endeavors, it was not unusual for them to have advisory boards, an objective body to guide the development and execution of the project's strategy. As client partnerships have become the project norm, advisory boards can serve an even greater utility, playing a more active role in shaping the project's activities, even participating in the project's data collection, analysis and application of the findings. The heightened engagement of the advisory board has shifted their view from outside observers to looking-from-within. It is this advisory board as an open forum for collaborative project involvement that we discuss here.

Watts-Englert utilized an advisory board to embark on a novel research project focused on informing the direction of Xerox's core business strategy. The Xerox Future of Work Project (Watts-Perotti et al. 2009, Watts-Englert et al. 2012) looked at the emerging trends on the cutting edge of work practice: mobility, distributed teamwork, communication, security, social media, and paper use. This project was exploratory and was not looking at the use of a specific product or technology, so the authors created an advisory board to anchor the research with practical business questions. Since the project did not fit the existing research mold, Watts-Englert strategically improved the odds for success by implementing an advisory board that would draw business group alliances into the project and promote the impact of the study's findings.

The goal of the advisory board was to garner visibility and support from relevant business groups and formalize a way to share project findings with these groups. Since the project's topic - the emerging trends of workers of the future -- was high interest and extremely timely, it attracted the attention of many in the organization. With membership open, the advisory board grew to more than 30 research and business group members, representing more than 14 groups across the company.

In partnering with the business groups, the researchers on the project encouraged product developers, business strategists and others to accompany the researchers into the field in order to see for themselves what the team was observing and documenting. While in the field, participant stakeholders were encouraged to help collect data and take ownership of their observations in the field, analyzing them and participating in project data sessions. By going out into the field, advisory board field workers helped shape the research questions in unanticipated ways, and their exposure to the contingencies of fieldwork helped push these business group members' thinking out of their box. The result was more productive discussions about the findings. The advisory board field experience closed the gap between the work practice findings and their significance for solution design, so discussions could focus on deepening the analysis and moving design solutions forward.

The advisory board enabled members to connect with people they had not met before, and forged alliances that might not have been possible without the creation of this new community of interest. An outgrowth of the meetings and email group was a community website, a gathering place for interested 
people across the company to share relevant papers and ideas about the research being conducted. The synergies that developed as a result of this intergroup participation eventually led to the creation of new cross-company teams to facilitate these emerging collaborations.

Exposing business groups and product developers to fieldwork is a growing trend. Some organizations are engaging in consulting projects where senior management accompany ethnographers into the field to learn about their customer population (see e.g. Schwarz 2011). Today's need for speed and development around fieldwork findings necessitates an efficient bridge. When corporate ethnographers are able to surrender some of their authority about fieldwork and data collection and invite their collaborators to accompany them into the field, a richer discussion around the implications of the findings can occur.

\section{Field Visits with Subject Matter Experts}

Many ethnographic studies involve different types of work, often in fields outside of the researcher's areas of expertise. Subject matter experts are both partners and participant stakeholders who provide relevant technical background information before going out into the field. Ethnographers gain background knowledge of the technology to be observed, making the observation more familiar and improving the quality of the observation and the questions. Providing background information to the ethnographers enforces the partnership between the team members, and helps the ethnographers to be fluent enough to understand the participants. The subject matter experts also contribute to the discussion guide containing the topics and range of questions to be investigated.

Subject matter experts played a strong role in a Xerox color digital printing project several years ago (Sprague, et al. 2007). A study was proposed to understand how color matching of digital prints was achieved before a digital production print job was run. In order to proceed with the work practice study in print shops, the researchers prepared for the study by gaining more background on the technology they would be studying. Color experts within the department provided an introductory course on the technical details of color and color imaging. The course provided the researchers with a familiarity with the technology and terminology they would hear in the field. During this preparation, the color imaging experts were also provided guidance about what to expect in the field and how to behave and ask questions. Ethnographers, subject matter experts and the study's customers jointly developed a discussion guide containing the lead questions to be investigated during the study.

Once the team was prepared and the initial field sites were determined, the research team, consisting of two ethnographers and a color imaging specialist, went out into the field. One of the main goals was to better understand how print operators used the tools provided with the digital color printers to achieve a color match to the original provided for the print job. The assumed process was for the print operators to create a test print, make any adjustments needed to match the colors, reprint the test, and once the colors were acceptable to the operator, provide the test print to the customer for approval before running the entire print job.

The observed process was not as straightforward. In many cases, the adjustments were made to the color printing device, rather than the electronic file. In other cases, the adjustments were made to the electronic file, rather than disturb the calibrations and settings of the color printer. In the cases where the color printer was adjusted, the color imaging specialist noticed that the print operators used the provided tools in ways that did not match the specifications as laid out by the system designers. The design specifications of the machine assumed that incoming files would include an electronic color profile that would allow the machine to automatically adjust settings to provide an acceptable print. However, in reality, many files did not include electronic color profiles. Therefore, adjustments to these files were done by eye, meaning the operators used their own experiences, combined with a trial and error technique, to match the colors. Few, if any, measurements were available to allow the operator to "dial in" the corrections in a systematic method. Of particular interest to the color imaging specialist was how the color adjustments were done contrary to the specifications laid out by the color consortium on how color printing was supposed to work. This was a surprising insight to the color expert, and these random 
adjustments and unexpected uses of the tools provided were not isolated; this was observed at several sites during the study.

The observations of adjustments that didn't fit the expected model helped pave the way for a sweeping redesign of the tools that were provided for the color digital printer. These new tools made it easier for operators to make color adjustments by eye, when no electronic color profiles were available. Several patents were generated, leading to the development of new, more intuitive color matching tools. In the end, the user interfaces for several tools were also redesigned to make the information more usable for print operators.

There were several benefits from the insights seen first hand by our partner stakeholder - the color imaging expert. At first, the expert had not believed that the systematic color corrections were not being followed, but seeing the corrections as they were being done awakened him to the truth. His observations convinced him of the importance of going into the field to see how work was actually being done and led him to become a strong advocate of work practice, both in the color printing study and beyond. It also inspired his future research to help the governing body of color specialists to better understand how to make their specifications less confusing and more usable for the people actually using printing devices. When the study findings were presented to the customer and other divisions within the company, this partner stakeholder provided recommendations and support that added technical credibility to these striking findings. In this way the subject matter expert was not only a partner stakeholder, but also became a promoter stakeholder, promoting not only the findings from the color printing study, but also promoting ethnographic methodologies in future projects.

\section{Analytic Data Sessions}

Ethnography is an empirical method strongly tied to the data that one collects at a particular field site of interest. One of the most effective ways for engaging a group of disparate members around an ethnographic project is by bringing a piece of this field data for collaborative analysis in the form of a data session. Xerox has a long history of using these types of co-viewing data sessions to build community and shared understanding around research project findings (Suchman and Trigg 1991; BrunCottan and Wall 1995; Jordan and Henderson 1995). It is common for the data session host to bring analytic aids such as transcripts or schematics that help the participants to see or make sense of the data being analyzed. These analytic aids help participants point to what they are seeing in the data and foster a productive, grounded discussion.

Once the observations and interviews have been completed, involving the stakeholders in the analysis of the findings and subsequent discussions is another way of involving interested parties. Once preliminary findings are available, it can be useful to have a brainstorming session with stakeholders and other parties to gain outside perspectives on the findings and resulting implications. Stakeholders often know numerous contacts and implications related to the fieldwork findings that may not be readily apparent to the ethnographers, offering an expanded view of potential opportunities and resolutions.

Participating in these analytic data sessions regularly throughout a study builds up a capacity to see interesting interactional phenomena and patterns across data excerpts. As participants talk about what they are seeing in the data, it is important to continually ask for the empirical evidence for what they are observing by asking: How do you know this? What evidence do you have? Over time, participants from non-social science backgrounds begin to develop an ethnographic stance: an attitude that simultaneously honors data and theory by pulling in concepts and patterns and checking them against the data that have been collected.

Data sessions are valuable for fostering stakeholder relationships at all phases of the project. For example at the very beginning of a new project, recorded ethnographic observations can be used in a data session format to inspire promoter stakeholder brainstorming of possible project topics. Mid-project, data analysis sessions engage partner stakeholders in the discovery of the research process. 


\section{Co-design as an iterative research process}

Ethnographic methods naturally lend themselves to collaboration, for in order to collect quality data in the field, trust and some degree of partnership with the participating members must be established. Codesign (Blomberg et al. 1993, Wall and Mosher, 1994), the collaborative creation of a solution or technology with the target user group, is a process that grows out of the relationship that ethnographers establish with the participant stakeholders with whom they are working In Xerox's iterative work practice methodology (see Figure 3), co-design begins with the first participant contact where it is communicated that no matter what type of project is at hand, the success of the project's outcome depends upon the relationship between the ethnographic researchers and the stakeholders who are involved.

Co-design workshops with participant and partner stakeholders can focus on process, technology, services and or organizational improvements. Sessions with Xerox stakeholders can bring customer experiences into focus for the community of researchers, technologists and planners who are interested in developing technologies and services for those customers. Workshops to engage stakeholders in field data and the implications for business include: data sessions to share and discuss excerpts of video data; intellectual property workshops focused on field findings and their implications for developing patents; ideation workshops to develop technology and service concepts; advisory board working sessions to share field findings and implications for various stakeholder constituents.

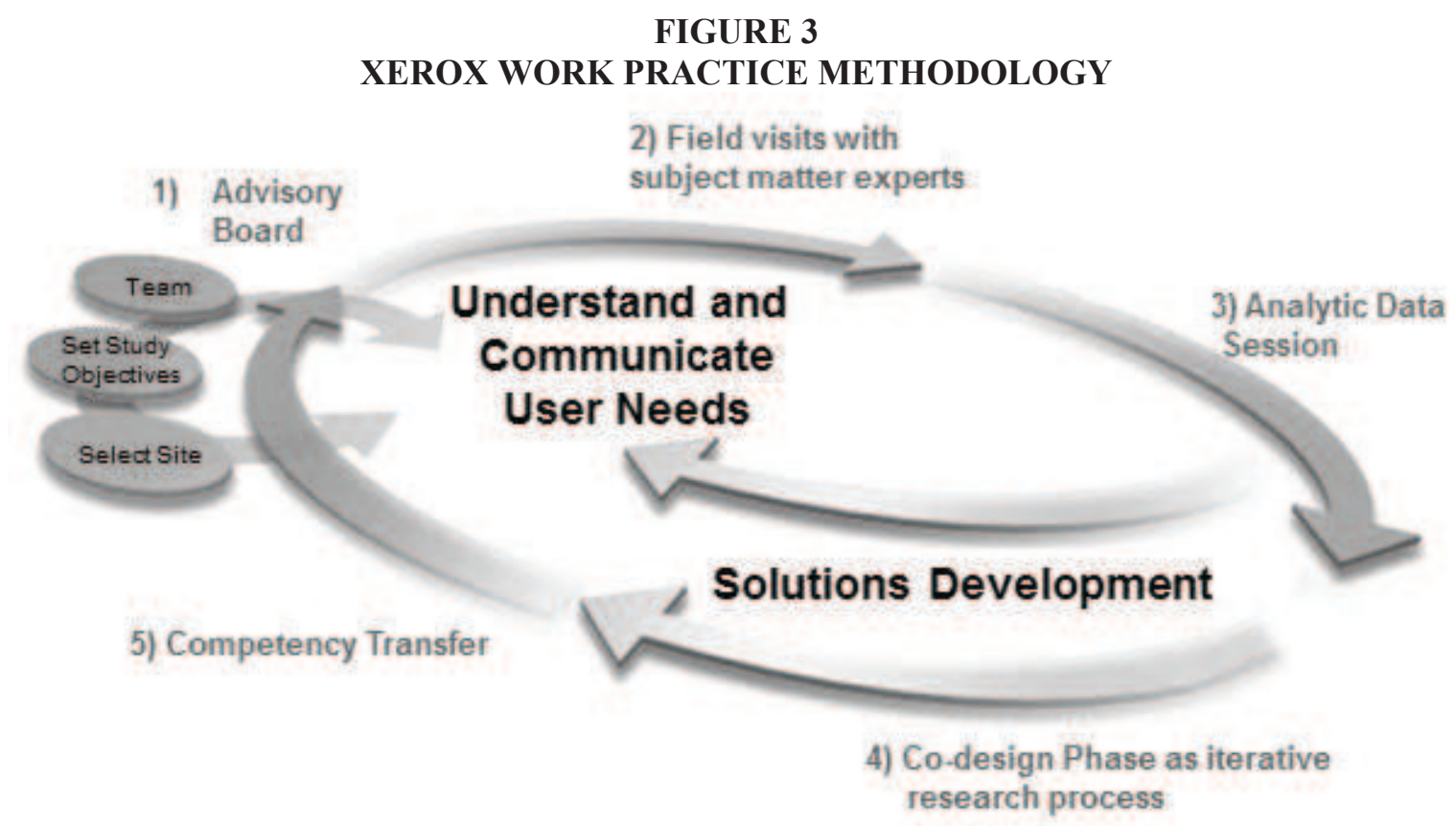

In partnering with the participant community in co-design, organizations are able to leverage and mobilize information from the people or environment in which the work is being accomplished. One project that translated ethnographic findings into a socio-technical system through a co-design process was the EUREKA Project (Whalen and Bobrow 2011). The project was originally focused on providing the Xerox customer service technicians with an online knowledge system (essentially the company's repair manual in digital form) to improve their repair of copier problems. Ethnographic observations revealed what the technicians really needed: a way to capture and share their own solutions to difficult, unknown, undocumented problems. So an expert system was co-designed around the technician work community; the technicians themselves would author and vet the solutions, so it would be 'owned' by the work community itself. Co-design enabled the technicians' knowledge and expertise to be captured and shared by technology that scaled their everyday face-to-face practices. 
In other co-design projects, the role of the workers can be center stage to the process. The Integrated Customer Service Project (Whalen and Whalen 2011) featured an experimental co-design process in which Xerox call agents, alongside Xerox researchers, created their own training program and a new learning environment. The project involved merging three different call center jobs into one new job enabling Xerox customers to dial a single 800 number to handle billing, supplies or service issues with their copier machine. In the co-design process, the workers themselves wrote a new training curriculum, based on their practical experience with a learning-by-doing instructional focus. Further, the co-design team changed the call center's physical environment to create an open, work-group centered environment that encouraged collaboration and sharing. Participation on the co-design team empowered the workers to take very active roles in making changes to improve their own performance and learning.

The way in which co-design plays out in any client partnership, and the degree to which the workers figure in the process, is particular to each client and their needs. In one retail copy shop project (Vinkhuyzen 2011), we combined the use of analytic data sessions and the co-design team to create a shared understanding with our client partner. The copy shop was having difficulty with its order-taking; almost every customer order had to be redone or added to at pick up because it had not been completed to the customer's specifications. To highlight the miscommunication that was happening during ordertaking, we brought videotaped excerpts of order-taking interactions to weekly meetings that featured thematic issues (e.g. upselling, discussing price, shop terminology, etc.), which we had discovered in our analysis. The employees on the co-design team (sometimes the ones in the video!!) would share their expertise by commenting on the data and brainstorm better ways of delivering customer service in these contexts. From these co-design data sessions, we were able to develop an online training program in customer service skills that used video recordings of actual customer encounters as one of the key instructional materials.

Co-design processes are partnerships with stakeholders that are tailored to the needs of the project. Depending on the desired outcomes of these engagements, stakeholder participation on the co-design teams can be peripheral or be positioned center stage to the solution development. Either way, the key is to develop a team that includes stakeholders who are invested in the process and outcome of the project; these champions will pave the way for the success of any technology intervention or process implementation.

\section{Competency Transfer}

Recently, some stakeholders have gone beyond a desire to benefit from ethnographic research to invest in creating an internal ethnographic competence. This has happened both inside Xerox and in a client organization. Through a process of competency transfer that involves classroom training and mentoring, employees within the stakeholder organization reach a level of proficiency in some ethnographic skills. Sometimes clients (both external and internal) request mentorship and learning workshops in addition to research on technology development or understanding customers. For example, a project for an external client on mobile telepresence (Isaacs et al. 2012) also involved the residency of a partner stakeholder to closely follow the research process. Recurrent requests to teach ethnographic field methods have resulted in the formalization of an ethnographic certificate program within Xerox.

One model for competency transfer mirrors more traditional learning trajectories including classroom and practical training phases with progression towards certification. Plurkowski et al. (2011) details an initiative to transfer work practice competency to subject matter experts in a Xerox business group that began to sell its services and solutions to clients outside of Xerox. The rationale for this stakeholder's investment in competency transfer was threefold. First, the organization had prior project successes that showed a work practice study could illuminate how the work is accomplished; these practices could be integrated into technologies, reducing production times and error rates. Second, they had made a commitment to strengthen the consulting methodology with a hybrid combination of normal process engineering methods and qualitative, employee-centered approaches such as the toolkit that work practice study provides. Third, whereas in the past the business group had asked research for help with their client 
engagements, they wanted to be able to singlehandedly provide end-to-end, integrated solutions themselves.

To transfer ethnographic competency to this internal Xerox business group, Xerox work practice analysts across three research centers developed training materials and workshops designed for professionals who were new to social science research, with the goal of creating a self-sustaining work practice training program. The Awareness level work practice (WP) training (see Table 1) was designed to be 90 minutes or less in order to fit into the extremely busy schedules of Xerox salespeople, and eventually was transformed into an e-learning module that could be deployed easily over the web. The Introductory level begins the certification path; managers and prospective work practice analysts take this one-day course to develop an intuitive sense for where work practice could be fruitfully applied. At the Apprentice level, candidates engage in a week-long classroom training that features a work practice study involving all phases of the work practice methodology in a real client site. Subsequently, apprentices engage in one or more additional work practice studies with the guidance of a mentor until adequate proficiency in the methodology is reached.

TABLE 1

TRAINING LEVELS OF WORK PRACTICE (WP) COMPETENCE

\begin{tabular}{|l|l|}
\hline Competence Level & \multicolumn{1}{c|}{ Description } \\
\hline 1. Awareness & "I can recognize an opportunity for WP value" \\
\hline 2. Introductory & "I can identify where to position WP as part of a solution" \\
\hline 3. Apprentice & $\begin{array}{l}\text { "I am training in WP methods" } \\
\text { - Classroom Training (Level 1): "I am learning WP methods." } \\
\text { - Field Training (Level 2): "I am practicing WP skills in the field." }\end{array}$ \\
\hline 4. Xerox Certification & $\begin{array}{l}\text { Certified Work Practice Analyst: } \\
\text { "I can effectively use work practice methods independently and } \\
\text { can contribute to a WP project team." }\end{array}$ \\
\hline $\begin{array}{l}\text { Expert Certification: Certified Work Practice Project Manager } \\
\text { "I can design and lead a work practice study effort." }\end{array}$ \\
$\begin{array}{l}\text { Certified Work Practice Trainer } \\
\text { "I can train others in Xerox WP (levels 1-4)." }\end{array}$ \\
\hline
\end{tabular}

Once certified, candidates are able to use work practice methods independently as an Analyst, or they may attain expert certification. The expert certifications acknowledge two roles: the Project Manager who oversees the resources and activities of a work practice team throughout the study, and the Trainer who is able to teach and mentor other candidates towards certification making the center self-sustaining.

Another project that also resulted in a self-sustaining center, the Fujitsu Social Science Laboratory, employed a different model of competency transfer (Kishimoto 2011). In this case, researchers relocated to Tokyo to mentor and work alongside the stakeholder-partner's employees. As PARC project lead Whalen (Kishimoto 2011:327) says, the center "was achieved not by Fujitsu copying PARC's ways of doing applied ethnography but rather by adapting our principles to their own operation, to their own 
organization's culture." This involved three years of mentoring and incubation inside the organization. Today, Fujitsu is using ethnographic fieldwork as a service to help their customers innovate their businesses.

Teaching ethnography as a service is not without its challenges. The most difficult thing to impart on novice practitioners is the analytic expertise needed to be able to "see" what the field data is revealing (Jordan 2011). Transferring ethnographic research skills to business group stakeholders also raises a key tension among practicing corporate ethnographers: should ethnography support technology-focused research or stand alone as the discovery science that it is? (Whalen and Whalen 2004). While this debate continues, we acknowledge that despite its challenges, of all the ways of working with stakeholders discussed here, competency transfer renders the strongest partnerships because of stakeholder's commitment and the time and investment required to achieve the transfer.

\section{MANAGING STAKEHOLDER INVOLVEMENT}

When involving stakeholders in the ethnographic research process, it is important to consider how their participation will impact the study. On the one hand, stakeholder participants could put an extra burden on ethnographers who must manage the presence of an additional person(s) and their behavior. On the other hand, stakeholder participants overwhelmingly turn out to be strong advocates for the research methodology, its findings and application. In the end, the benefits stakeholder participants bring to the research process outweighs any additional work, but here are some of our best practices for success.

In all situations, bringing people into the field with you is a concern because it can affect your rapport with customers and impact the way they interact with you. Whereas interviewing a participant alone sets up a manageable dyadic interaction, bringing along one or more stakeholders can create an uneasy two or three-against-one dynamic making the participant feel insecure about speaking freely. Moreover, if stakeholders do not feel comfortable going into the field, the uneasiness of the interaction is increased, further impacting the researcher's ability to gather data and build trust with the study participants. One way to effectively manage stakeholder participants is to introduce them to study participants early on in the project so familiarity and trust can be established.

Since partner stakeholders may not have previous experience with ethnographic methods, it is important to provide an overview of the approach, training regarding observation and interviewing techniques, and to set expectations for their role in the field. If possible, ask them to take a role in the field activity, for example taking responsibility for audio recording, to make them an integral part of the team rather than a tag-a-long observer. Also clarify expectations about interactions at the field site, e.g., if they are participating in an interview, clarify what the expectations are for introducing topics or questions so they do not inadvertently interrupt, or worse, derail, the flow of the interaction. You can also ask them to summarize their experience including their impressions, any surprises or insights, so they take the opportunity to reflect on the experience and contribute to the data analysis.

Another concern when involving stakeholders in the research process is their ability to learn how to conduct themselves as objective observers, and be open to learning about participants' work practices and points of view. It is not uncommon for stakeholders to jump to conclusions too early based on a small amount or a subset of the data, especially when they have a pre-conceived agenda they would like to reinforce. For example, some stakeholders may come to the field with their own ideas for what new features should be incorporated into a product, and they may attempt to confirm the validity of these concepts in the field, rather than being open to understanding the work practices of the participants. Further, in an interview situation, stakeholders can unknowingly bias their interactions with participants by asking leading questions (e.g. "that process results in errors, doesn't it?" Or how would you like it if the product had this new feature in it?").

A great way to manage novice stakeholder participants is to give them guides for their expected field behavior; their performance aids can remind them of the appropriate stance they should take with study participants and give them a list of unbiased questions the study aims to answer. Workshops can be a constructive way to engage stakeholders with study data and encourage in-depth discussions around the 
emerging results and their implications for stakeholder interests. Organizing working sessions with stakeholders doesn't have to wait until data collection and analysis are complete. Interactions that take place early on in a study not only help stakeholders connect with the data; they can provide an opportunity for stakeholders to provide insights, add new questions to the study, verify or clarify findings, suggest new contacts for fieldwork and build trust with the research team.

Stakeholders who accompany researchers into the field prove to be valuable allies in the research process. Stakeholders bring their own expertise to the field, which may lead them to notice things that the ethnographers might miss. In addition, by participating in the research process, stakeholders can develop their own understanding and empathy with participants; to convey this in other ways would be much more time consuming and less successful. So, when considering the time invested in taking stakeholders to the field, consider the time saved in recruiting a knowledgeable champion for the findings of the current ethnographic study as well as potential future work.

Despite the extra work bringing stakeholders into the field may cause, it is still worthwhile for several reasons. Most importantly, stakeholders who have been brought into the field have repeatedly stated that it has given them an appreciation for ethnographic research and the value of its findings. This first-hand observation often helps stakeholders to better see the complexity of the work done by participants and the conditions that are worked under that may often change outcomes. It has often been seen that such on-site observation can help to validate the findings in ways that cannot be duplicated by reports or videos. When stakeholders buy into the research method and its findings, they are more likely to serve as champions for ethnographic projects in the future. Not only do stakeholders who have gone into the field use ethnographic findings more readily, they also share these findings with colleagues which can accelerate the adoption of organizational change.

Managing stakeholders is both about optimizing their participation with the study participants in the field and leveraging their role within the stakeholder organization. With a little pre-planning, stakeholder participants can become savvy observers and interviewers that bring their own unique perspective to enhance the study's outcome. Once stakeholder participants have been in the field, they more readily communicate their experience with their organization and increase the chances that the study will have impact, especially if the study findings are packaged for distribution (e.g. podcast, brochure, power point, etc.).

\section{TYPES OF IMPACTS RESULTING FROM COLLABORATION WITH STAKEHOLDERS}

Collaborating with stakeholders can have significant impacts along a range of dimensions.

Among the most obvious impacts are those captured in the form of new products, features, technologies or services. This was the case in a study with a university bookstore where a collaboration around the design of a system to create custom course packs resulted not only in improvements to the course pack creation technology, but also identified a need for a copyright management system to automate the labor intensive process of obtaining and tracking copyright permissions from publishers for course pack materials. This system was developed and was added as a product offering.

In some instances, new ideas or improvements can be realized as intellectual property. This was the case in a study of production print environments, where observations of production print shop operators resulted in the design of an improved color editing capability. Insights from the field illustrated operator struggles with a multi-layered color editing tool, as described above (Sprague et al., 2007). This led to an improved design embodied in a patent, which was implemented and incorporated in subsequent releases of the product software.

Collaborations with stakeholders can lead to new service offerings or expand existing lines of business. A new line of business at Xerox, which focused on student assessments for K-12 schools grew from a research collaboration with local school districts, initially to explore teaching practices and opportunities to support teachers in achieving educational objectives (Sprague 2013). To date, this collaboration has resulted in the development of a product (Xerox Ignite Educator Support System ${ }^{\mathrm{TM}}$ ) 
aimed at facilitating student assessments and personalized instruction in the classroom. This represents a new capability and market opportunity for Xerox.

Collaborations with stakeholders can uncover new market opportunities as well as influence strategy directions. The Future of Work project (Watts-Englert et al. 2011) explored socio-technical trends (e.g., alternative work settings, increasing mobility, a digital savvy workforce) and how work is changing. The project uncovered real world practices and generated thought provoking implications about paper-todigital transitions and the future use of paper in business processes, topics that were incorporated into corporate strategy planning workshops. The project also identified a high potential new market - mobile workers. We studied that in depth in partnership with a technology team, who decided to develop solutions for that market - in part inspired by the findings from the Future of Work project.

Ethnographic study findings also become woven into stakeholders' daily work. We've seen several instances where project findings embodied in slides and illustrations have been incorporated into stakeholder plans and presentations. Stakeholders have also helped convince other stakeholders to take action based on study findings. The color printing project described earlier is an example of this. An imaging scientist who accompanied us to the field became one of our strongest voices into the product development community, resulting in significant improvements embodied in subsequent product releases.

\section{CONCLUDING THOUGHTS}

Corporate research is evolving: financial hard times require researchers to seek client partnerships for funding. Industry partners are also evolving to seek out and embrace research processes in new ways. Corporate ethnography, a methodology that naturally engages customers, has fared well in this corporate research evolution and several techniques have been used to strengthen these partnerships.

Within Xerox, several methods have been used to draw stakeholders into ethnographic research projects. Advisory boards enable peripheral stakeholders to shape the direction of the research and build momentum in the community for new ideas, technologies and change. Field visits with subject matter experts set up for a strong research partnership as these stakeholders not only often provide entrée to the field but also facilitate the dissemination of the study findings for impact. Analytic data sessions enable stakeholders to look across interdisciplinary boundaries and actually see their customers and identify opportunities for products and solution development. Co-design practices that engage stakeholders in an iterative research process make it possible to harness this stakeholder knowledge and expertise to create better solutions and improved ways of working; the process delivers impact that the stakeholders themselves "own". And businesses are investing in ethnographic competency transfer to bolster their internal capacity to deal with their clients' problems and to create new service offerings.

Xerox ethnographic research has embraced stakeholders by inviting them to participate in the collection and analysis of field data. Analytic data sessions, advisory boards as field alliances, field visits with subject matter experts, co-design, and competency transfer are five activities that enable researchers and stakeholders to develop a common understanding grounded in data. As a result, ethnographic research and business stakeholders are becoming more closely aligned and heightening the potential impact of their collaborative projects.

While it can be challenging to involve stakeholders in the research methodology, these challenges can be addressed. Ultimately it is worth the extra work to address these challenges, given the benefits of involving stakeholders in the research methodology. When stakeholders are involved, the research is more grounded, and has a greater potential to generate actionable study implications. Involved stakeholders can also increase the likelihood that study findings are incorporated into future products or services.

\section{REFERENCES}

Blomberg, J., Giacomi, J., Mosher, A. \& Swenton-Wall, P. (1993). Ethnographic Field Methods and Their Relation to Design, In D. Schuler and A. Namioka (Eds.), Participatory Design: 
Perspectives on Systems Design, Lawrence Erlbaum Associates, Hillsdale, NJ, 123-156.

Brun-Cottan, F. \& Wall, Patricia. (1995). "Using Video to Re-Present the User", Communications of the $A C M$, Vol. 38, No. 5 61-71.

de Kleer, J., Whalen, M., Whalen, J. (2004). Leveraging the Social, Unpublished Internal Report, PARC Inc.

Colombino, T., O’Neill, J., Martin, D., Grasso, A., Wilamowski, J., Roulland, F., Sprague, M.A. \& Watts-Perotti, J. (2011). Seeing the right colour: Technical and practical solutions to the problem of accurate colour reproduction in the Digital Print Industry, in P. Szymanski (ed.), Making Work Visible: Ethnographically grounded case studies of work practice, Cambridge University Press.

Isaacs, E., Szymanski, P., Yamauchi, Y., Glasnapp, J. \& Iwamoto, K. (2012). Integrating Local and Remote Worlds Through Channel Blending, CSCW'12, Seattle, WA, USA.

Jordan, B. (2011). Transferring Ethnographic Competence: Personal Reflections on the Past and Future of Work Practice Analysis, In Szymanski, M. H. and Whalen, J. (eds.) Making Work Visible: Ethnographically grounded case studies of work practice, Cambridge University Press, New York, 344-358.

Jordan, B. \& Henderson, A. (1995). Interaction Analysis: Foundations and Practice, The Journal of the Learning Sciences, 4(1), 39-103.

Kishimoto, K. (2011). Fujitsu learned Ethnography from PARC: Establishing the Social Science Center. In Szymanski, M. H. and Whalen, J. (Eds.), Making Work Visible: Ethnographically grounded case studies of work practice, Cambridge University Press, New York, 327-335.

Lerner, G. H. (2012), Personal communication.

Plurkowski, L., Szymanski, M. H., Wall, P. \& Koomen, J. A. (2011). The Work Practice Center of Excellence, In Szymanski, M. H. and Whalen, J. (Eds.) Making Work Visible: Ethnographically grounded case studies of work practice, Cambridge University Press, New York, 336-343.

Schwarz, H. (2011). Ethnography as Executive Exposure - Spectacle or Higher Education? Ethnographic Praxis in Industry Conference, Boulder, CO, September 2011.

Slywotzky, A. (2009). Where Have You Gone, Bell Labs? Bloomberg BusinessWeek Magazine. August 27, 2009, http://www.businessweek.com/magazine/content/09_36/b4145036681619.htm.

Sprague, Mary Ann; Maryann Fuhrmann (2013); “Ethnography Supports Changes to Student-Centered Instruction”, TQR 4th Annual Conference, Ft. Lauderdale, FL, http://www.nova.edu/ssss/QR/TQR2013/sprague_fuhrmann.pdf.

Sprague, Mary Ann, Martin, Nathaniel, Wall, Patricia \& Watts-Perotti, Jennifer. (2007). Giving Voice to Print Production Facility Workers: Representing actual work practices in the streamlining of a labor intensive production print job. Ethnographic Praxis in Industry Conference, Keystone, CO, 2-4.

Sprague, Mary Ann, Woolfe, G., Watts-Perotti, J., Martin, D., Colombino, T. \& O’Neill, J. Ethnographic Studies of Digital Prepress Color Workflows. ISCC Annual Meeting, Kansas City, MO, April 2930, 2007.

Suchman, L. (1992). Technologies of Accountability: Of Lizards and Airplanes. In G. Button (ed.), Technology in Working Order: Studies of Work, Interaction and Technology, Routledge, London, 113-126.

Suchman, L. (1995). Making Work Visible. Communications of the ACM, September 1995, Vol. 38, No. 9, 56-64.

Suchman, L. (1996). Constituting Shared Workspaces, In Y. Engeström and D. Middleton, (eds.). Cognition and Communication at Work, Cambridge University Press, Cambridge, 35-60.

Suchman, L. (2011). Work Practice and Technology: A Retrospective. In Szymanski, M. H. and Whalen, J. (Eds.). Making Work Visible: Ethnographically grounded case studies of work practice, Cambridge University Press, New York, 21-33.

Suchman, L. A., \& Trigg, R. H. (1991). Understanding practice: Video as a medium for reflection and design, In J. Greenbaum and M. Kyng (Eds.). Design at Work: Cooperative Design of Computer 
Systems, Erlbaum, Hillsdale, NJ, 65-90.

Wall, P., Brun-Cottan, F., \& Dalal, B. (2008). Work Practice in Education, Unpublished manuscript.

Wall, P. \& Koomen, J. A. (2011). Designing Document Solutions for Airline Maintenance Advisories, In Szymanski, M. H. and Whalen, J. (Eds.), Making Work Visible: Ethnographically grounded case studies of work practice, Cambridge University Press, New York, 285-298.

Wall, P. \& Mosher, A. (1994). Representations of work: Bringing designers and users together, In PDC '94: Proceedings of the Participatory Design Conference (Palo Alto, CA), Computer Professionals for Social Responsibility, 87-98.

Watts-Perotti, J., Sprague, M. A., Wall, P. \& McCorkindale, C. (2009). Pushing New Frontiers: Examining the Future of Paper and Electronic Documents. Ethnographic Praxis in Industry Conference Proceedings, Volume 2009, Issue 1, August 2009, Chicago, IL, 197-208.

Watts-Englert, J., Sprague, M. A., Wall, P., McCorkindale, C., Purvis, L. \& McLaughlin, G. (2011). Exploring Documents and the Future of Work, In Szymanski, M. H. and Whalen, J. (Eds.). Making Work Visible: Ethnographically grounded case studies of work practice, Cambridge University Press, New York, 109-127.

Watts-Englert, J., Szymanski, M., Wall, P., Sprague, M. A. \& Dalal, B. (2012). Back to the Future of Work: Informing Corporate Renewal. Ethnographic Praxis in Industry Conference, Savannah, GA.

Whalen, J. \& Bobrow, D. G. (2011). Communal Knowledge Sharing: The Eureka Story, In Szymanski, M. H. and Whalen, J. (Eds.). Making Work Visible: Ethnographically grounded case studies of work practice, Cambridge University Press, New York, 257-284.

Whalen, J. \& Whalen, M. (2011). Integrated Customer Service: Re-inventing a workscape, In Szymanski, M. H. and Whalen, J. (Eds.). Making Work Visible: Ethnographically grounded case studies of work practice, Cambridge University Press, New York, 181-204.

Whalen, M. \& Whalen, J. (2004). Studying Workscapes, In P. LeVine and R. Scollon (Eds.). Discourse and Technology: Multimodal Discourse Analysis, Georgetown University Press, Washington, D. C., 208-229. 